\title{
Luto, religiosidade e espiritualidade: um estudo clínico-qualitativo com viúvas idosas
}

\author{
Mourning, religiosity and spirituality: a clinical-qualitative study of aged widows
}

Luto, religiosidad y espiritualidad: un estudio clínico-cualitativo con viudas ancianas

\author{
Adriano Luiz da Costa Farinasso ${ }^{1}$, Renata Curi Labate ${ }^{2}$
}

\section{RESUMO}

O presente estudo objetivou compreender os significados da vivência do luto em viúvas idosas e sua relação com a religiosidade e espiritualidade. Trata-se de uma pesquisa clínico-qualitativa realizada com seis viúvas idosas. Os dados foram coletados entre outubro de 2009 e agosto de 2010 por meio de entrevistas não estruturadas e analisadas por categorias temáticas. Do escopo de resultados encontrados, destacam-se: as crenças religiosas podem contribuir na construção de significado para o luto facilitando sua elaboração; a igreja serviu como apoio às viúvas ao proporcionar um espaço de socialização e de expressão de sentimentos; e a religiosidade intrínseca e extrínseca foram verbalizadas como protetoras da depressão e de sentimentos de solidão. Conclui-se que a religião e a espiritualidade possuem um papel positivo na elaboração do luto chamando atenção para que os enfermeiros que lidam com situações de luto e morte busquem integrar as crenças religiosas dos indivíduos sob seus cuidados.

Descritores: Pesar; Idoso; Religião; Espiritualidade; Cuidados de Enfermagem.

\section{ABSTRACT}

The objective of the present study was to understand the meanings of the mourning experience and its relationship to religiosity and spirituality. This is a clinical-qualitative study performed with six aged widows. Data were collected between October 2009 and August 2010 by means of non-structured interviews and were analyzed utilizing thematic categories. The highlights from the results are: one's religious beliefs may contribute towards building meaning in mourning, thus facilitating its elaboration; the Church serves as a source of support for the widows by providing a place for socialization and the expression of feelings; and intrinsic and extrinsic religiosity are verbalized as forms of protection against depression and feelings of loneliness. In conclusion, religion and spirituality play a positive role in the elaboration of mourning, which necessitates the attention of nurses who deal with situations of death and mourning to integrate the religious beliefs of their patients.

Descriptors: Grief; Aged; Religion; Spirituality; Nursing Care.

\section{RESUMEN}

Se objetivó comprender los significados de la vivencia del luto en viudas ancianas y su relación con la religiosidad y espiritualidad. Investigación clínico-cualitativa realizada con seis viudas ancianas. Datos recolectados de octubre 2009 a agosto 2010 mediante entrevistas no estructuradas, analizadas por categorías temáticas. Del punto de resultado encontrado. Entre los resultados encontrados, se destacan: las creencias religiosas pueden contribuir en la construcción del significado del luto, facilitando su elaboración; la iglesia sirvió como apoyo a las viudas al proporcionar un espacio de socialización y expresión de sentimientos y, la religiosidad intrínseca y extrínseca fueron verbalizadas como protectoras contra la depresión y la soledad. Se concluye en que la religión y la espiritualidad poseen un rol positivo en la elaboración del luto, llamándose la atención de los enfermeros que enfrentan situaciones de luto y muerte para que busquen integrar las creencias religiosas de los individuos bajo sus cuidados.

Descriptores: Pesar; Anciano; Religión; Espiritualidad; Atención de Enfermería.

\footnotetext{
1 Enfermeiro, Mestre em Enfermagem. Discente do Programa de Pós-Graduação em Enfermagem Psiquiátrica, nível Doutorado, da Escola de Enfermagem de Ribeirão Preto da Universidade de São Paulo (EERP/USP). Professor da Universidade Norte do Paraná. Londrina, PR, Brasil. E-mail: adriano.farinasso@unopar.br.

${ }^{2}$ Enfermeira, Doutora em Enfermagem Psiquiátrica. Professora Doutora da EERP/USP. Ribeirão Preto, SP, Brasil. E-mail: labatere@eerp.usp.br.
} 


\section{INTRODUÇÃO}

O envelhecimento populacional, caracterizado pelo aumento da proporção de idosos na população, é um fenômeno emergente não só nos países desenvolvidos. Este processo, denominado transição demográfica, vem acontecendo no Brasil de forma acelerada com um declínio rápido dos níveis de fecundidade e de mortalidade aliados ao aumento da longevidade ${ }^{(1)}$. Esta transição não ocorre de maneira igual entre os gêneros, sendo que, com o avançar da idade, o número de mulheres em relação aos homens é maior. Ainda, a proporção de viúvas na população idosa é superior a de viúvos em qualquer faixa etária(2-3).

Neste contexto epidemiológico, é presumível que a vivência do processo de luto pela perda do cônjuge seja uma experiência comum entre mulheres idosas devido à maior expectativa de vida e maior taxa de mortalidade entre os homens idosos ${ }^{(3)}$.

O luto pode ser definido como uma constelação de reações e comportamentos desencadeados pelo rompimento de um vínculo existente entre duas pessoas $^{(4)}$. Para o idoso, este rompimento pode gerar graves consequências à sua saúde física e mental apesar da relação entre o avançar da idade e a elaboração do luto ainda não estar clara na literatura ${ }^{(5)}$. O risco de múltiplas e sequenciais perdas de familiares e amigos, aliado ao declínio funcional e a perda do status social decorrentes do envelhecimento, podem fazer com que a experiência de luto do cônjuge seja vivenciada como um evento de sobrecarga ${ }^{(6)}$. Em adição, muitos idosos vivem em situação de risco, com problemas financeiros, isolados e com doenças graves que podem se agravar com as perdas da vida, constituindo o que se denomina sobrecarga de luto ${ }^{(7)}$. Em contrapartida, o aumento da resiliência em idosos enlutados, entendida como a capacidade de adaptar-se a eventos adversos considerando a vivência de crises anteriores, deve ser considerado como um fator facilitador do enfrentamento do luto(8).

Dentre os fatores que facilitam o enfrentamento e a elaboração do luto, é particularmente importante considerarmos os aspectos religiosos e espirituais do indivíduo em luto. Tais aspectos atribuem significados aos eventos de vida, permitindo ao enlutado compreender sua história e elaborar o luto mais facilmente ${ }^{(9)}$.
A religiosidade e a espiritualidade dos idosos aumentam com o passar dos anos por servir de explicação para os questionamentos relacionados ao sentido da vida. A espiritualidade revela-se como um indicador de resiliência, pois permitiu a atribuição de significados aos eventos negativos ${ }^{(10)}$.

Neste contexto, consideramos como pressuposto para o presente estudo, que os significados de morte e luto ligados às crenças religiosas e a espiritualidade podem interferir na elaboração do luto, configurando-se em um campo a ser trabalhado pelos enfermeiros ao lidarem com idosos enlutados. Assim, esta pesquisa objetiva compreender os significados da vivência do luto em viúvas idosas e sua relação com a religiosidade e espiritualidade.

\section{MÉTODO}

Para esta pesquisa, adotamos o método clínicoqualitativo(11) pela adequação de suas características com os objetivos propostos neste estudo. Trabalhar com pessoas enlutadas carrega, dentro do próprio tema, uma carga intensa de sofrimento, de sentimentos e angústias vividas e expressadas durante a pesquisa. A possibilidade de se colocar frente à pessoa enlutada e compartilhar com ela as ansiedades e angústias advindas da vivência da perda faz com que o pesquisador busque a compreensão das questões propostas identificando-se com o outro. Essa atitude existencialista, característica do método clínico-qualitativo, permite que o pesquisador acolha as angústias e ansiedades deste, possuindo, assim, uma atitude clínica, com olhos e ouvidos qualificados para compreender existencialmente os sofrimentos que acometem o outro $^{(11)}$.

Esta pesquisa ocorreu dentro da área de abrangência do Programa de Saúde da Família (PSF) do município de Arapongas-PR. Trata-se de um município de aproximadamente 100 mil habitantes, localizado ao norte do Estado do Paraná e caracterizado como polo industrial moveleiro da região.

Para seleção dos sujeitos foi adotada uma amostra intencional por variedade de tipos composta por seis mulheres idosas que vivenciaram o processo de luto do cônjuge, selecionadas a partir dos registros das Equipes de Saúde da Família. A definição do número amostral aconteceu mediante a saturação da amostra, ou seja, 
após certo número de sujeitos pesquisados, novas entrevistas passaram a apresentar certa redundância ou repetição(12).

Os critérios de inclusão das participantes foram: a) possuir idade igual ou maior que 60 anos; b) ser do sexo feminino; c) residir em área urbana e de abrangência do PSF do município de Arapongas; d) ter vivenciado a morte do marido há mais de um mês e menos de 13 meses antes da data da entrevista; e) concordar em participar do estudo.

Os dados foram coletados por meio de visitas domiciliares entre outubro de 2009 e agosto de 2010. As entrevistas foram conduzidas utilizando-se a técnica de entrevista não estruturada com uma questão disparadora de verbalização. As falas das participantes foram gravadas em áudio digital e as impressões sobre o comportamento e expressão emocional foram anotadas em diário de campo. Seguindo os preceitos do método clínico-qualitativo a pessoa do investigador serviu como o instrumento principal da coleta e registro dos dados, pois, são suas percepções que apreendem os fenômenos e sua consciência que os representa e elabora.

A análise dos dados realizou-se conforme as técnicas de análise de conteúdo descritas especificamente para o método clínico-qualitativo(11). Primeiramente, procedeuse a leituras flutuantes do material coletado até uma espécie de impregnação do seu conteúdo. Após a classificação dos elementos por diferenciação foi realizado o reagrupamento das falas gerando as categorias de análise.

O presente trabalho foi aprovado pelo Comitê de Ética em Pesquisa da UNOPAR, mediante o protocolo $n^{\circ}$ PP 0222/08 e seguiu as normas e diretrizes regulamentadoras de pesquisa em seres humanos dispostas na Resolução 196/96 CNS, garantindo a participação por livre e espontânea vontade com assinatura do Termo de Consentimento Livre e Esclarecido. Os sujeitos foram identificados por nomes fictícios, preservando assim o anonimato das participantes.

\section{RESULTADOS E DISCUSSÃO}

Ao todo foram entrevistadas seis viúvas idosas com idade entre 61 a 83 anos. Três participantes eram católicas e as outras evangélicas, sendo uma da Congregação Cristã do Brasil, uma da Igreja
Presbiteriana Renovada e a outra da Igreja Deus é Fiel. O tempo de luto variou entre um a oito meses.

A apresentação dos resultados obtidos nas entrevistas foi exposta e organizada em agrupamento de categorias, sem pretensão de hierarquização dos dados a partir de sua importância presumida ou da frequência de aparecimento nas falas. Por se tratar de uma pesquisa mais abrangente, foram elencadas três categorias para apresentação neste artigo. A escolha destas categorias deu-se pela relevância em relação ao tema e a correlação com os objetivos propostos neste artigo. Ainda, não se pretende aqui, apresentar resultados generalizáveis além da amostra pesquisada, sendo que, as inferências e interpretações desenvolvidas neste artigo referem-se, exclusivamente, ao contexto em que se realizou a pesquisa. Porém, a reflexão destes achados pode servir de tema para reflexão na compreensão do trabalho de luto em idosos em um contexto mais abrangente.

\section{A fé em Deus como combustível para a superação do luto.}

A fé em Deus e as crenças religiosas que determinam a visão de mundo das viúvas entrevistadas aparecem de forma explícita nos relatos. Uma parte das entrevistadas deixou claro que a fé em Deus funciona como um "propulsor", certo tipo de "combustível" para que a perda do marido seja superada, e a dor do luto seja substituída por pensamentos e sentimentos positivos. A fala de Divina deixa evidente essa "positividade" com o uso das palavras "força" e "coragem":

[...] que ajudou mesmo foi Jesus, me deu força, me deu coragem pra eu aguenta e to aqui em pé! [...] (Divina).

A palavra força é definida como vigor, robustez, saúde física, poder, energia física e energia moral, dentre outras definições. Já o termo coragem significa força ou energia moral que leva a afrontar perigos ${ }^{(13)}$. Coragem vem do latim coraticum e refere-se à habilidade de confrontar o medo, a dor, o perigo a incerteza e a intimidação. O relato de Divina nos mostra que sua fé em Deus, representada por Jesus, parece dar-lhe a habilidade de lutar contra a dor da morte do marido em um processo orientado para a restauração da perda.

A fé implica na imagem de um Deus misericordioso e cuidador. A vivência do luto proporciona uma 
aproximação com Deus, buscando forças para lidar com a perda e com o sentimento de impotência ${ }^{(14)}$. Ainda, a fé em Deus aparece como algo que evita ou previne a depressão:

[...] é porque se a gente não tiver fé em Deus, não se apegar a ir pra igreja, rezar, tomar comunhão né [...] todos domingo eu vou à missa, se não fosse isso eu tinha entrado em depressão eu acho né, então isso ajuda muito a gente não entrar em depressão! (Benedita)

Existem controvérsias entre estudos que avaliam aspectos religiosos e depressão em enlutados. Quando o enfrentamento religioso enfoca a crença na vida após a morte geralmente são observadas associações positivas em relação ao humor dos enlutados. Entretanto, a religiosidade extrínseca, representada pela participação em cultos ou templos, não produz os mesmos efeitos ante o pesar e a depressão(9).

O discurso acima está carregado de elementos que denotam a religiosidade extrínseca(15) (participação em cultos, missas e reuniões) como protetora da depressão. Entretanto, o conteúdo geral de sua fala traz elementos importantes de espiritualidade e fé, característicos de forte religiosidade intrínseca(15) (crença subjetiva em Deus ou alguma força maior). Apesar de a literatura ${ }^{(5,9)}$ apresentar pontos contraditórios sobre a associação entre religiosidade e depressão em enlutados, podemos inferir, neste caso, que tanto aspectos de religiosidade intrínseca quanto extrínseca foram verbalizados como protetores da depressão. Complementando essa discussão, outra entrevistada relata que a fé em Deus tem a capacidade de evitar crises de desespero e angústia:

[...] eu não tenho motivo de chorá, eu só tenho motivo de agradecê a Deus por o que Ele vem fazendo. Porque se eu não conhecesse Deus eu ia me descabelá, ia chorá muito né [...] quando eu entro em desespero, eu começo a clamá Deus, peço pra Deus ter misericórdia, porque a gente sem Deus não é nada né! [...] A gente vê assim que na hora da aflição, Deus vem e tira aquela angústia, já começo a pensá outra coisa [...] (Eva).

A leitura das frases acima nos permite visualizar claramente elementos de religiosidade intrínseca servindo como combustível para superar o processo de luto. Ainda, percebemos que a fé em Deus apresenta-se como redirecionador dos pensamentos ligados à perda para ideias ligadas a restauração e superação da perda.

Ainda, a fé e as crenças religiosas podem ajudar a viúva a amenizar os sentimentos de solidão advindos da morte do marido. A perda do cônjuge priva a pessoa enlutada do suporte de vida cotidiano e da participação social. A solidão pode ser considerada um fator de risco para pior elaboração do luto(16).

O pesar é uma reação a perda e solidão é uma reação à privação. A privação significa a falta de suprimentos essenciais que foram anteriormente fornecidos pelo falecido. Esses elementos que ficaram ausentes após a perda têm origem diversa. Na maioria das vezes, são aspectos básicos, estabelecidos na relação de apego(17).

Para Amélia, um desses elementos básicos perdidos junto com a morte do marido é a companhia para dormir:

[...] todo mundo pergunta: 'a senhora ta dormindo sozinha?' Eu falei não, to dormindo com Deus, companhia minha é Deus, falei pra eles né [...] to continuando sozinha com fé em Deus, só com Deus [...] (Amélia).

Na leitura da fala acima, fica perceptível como a enlutada utiliza a sua fé em Deus para preencher as lacunas da perda. Рara ela, a companhia de Deus promove um alívio da solidão, sendo isso verbalizado a outras pessoas. Entretanto, observa-se ambivalência em seu discurso quando diz "não, to dormindo com Deus" e logo após complementa "to continuando sozinha com fé em Deus".

\section{A fé como transformadora do significado da morte}

Vivenciar o momento da morte de um ente querido pode, para muitos, resultar em lembranças e sentimentos de separação, ausência, perda e horror. A lembrança do falecido ou quaisquer outras situações onde há a reativação do sistema de apego referem-se ao enfrentamento voltado para a perda dentro do Modelo Dual do Luto ${ }^{(17)}$. Este modelo descreve o enfrentamento do luto como uma oscilação entre duas orientações psicológicas, o enfrentamento orientado para a perda e outro que é orientado para a restauração. Assim, a elaboração do trabalho de luto depende da oscilação dessas duas orientações de tempos em tempos, 
permitindo a sua resolução ou complicação. Portanto, a lembrança da morte, ou, especificamente, do momento da morte do marido relaciona-se, teoricamente, com o enfrentamento orientado para a perda.

Apesar da representação de morte comumente resultar em algo doloroso e terrível, as lembranças do momento da morte podem manifestar sentimentos de paz e calmaria, considerando, especialmente, o alicerce religioso de cada indivíduo. Esse sentimento de paz ao lembrar-se da morte do marido fica evidente na fala de uma das entrevistadas:

[...] na hora dele morrê foi tão lento que ele fico me olhando, fecho o olho devagarinho [...] e rezando, ai ele foi em paz que não deu movimento nenhum. Então marcou aquela hora que ele se foi né, que ele se foi me olhando, olhando, devagarinho e foi e foi [...] ai eu fico muitas vezes sozinha e fico imaginando o sofrimento dele, imaginando a morte dele, que foi uma morte muito bonita [...] (Cecília).

Vale a pena ressaltar que durante as verbalizações descritas acima, a entrevistada apresentava um semblante de paz e alívio ao recordar do momento da morte de seu marido. O medo da morte diminui nas pessoas mais religiosas, sendo que, os religiosos e os ateus convictos têm menos medo da morte que os medianamente envolvidos(7). Em nosso entendimento, isso pode ser estendido à morte de outros, ou seja, ao processo de luto.

Outro ponto a ser destacado é o significado atribuído para o que se espera "além" da morte. As religiões em geral tratam exaustivamente da questão da morte, ocupando um lugar central em seus ensinamentos. Nesses ensinamentos, a crença de que a morte representa uma transição do espírito para um "lugar melhor" onde os perjúrios e sofrimentos da vida terrena não existem mais, pode permitir ao enlutado construir significados positivos à experiência.

Metade das viúvas estudadas deixou explícito em suas falas que a morte do esposo foi "obra de Deus", e como crentes, essa perda, apesar de toda a dor, deve ser aceita de maneira inquestionável:

[...] acho que a gente tem o dia da gente né...que Deus chama a gente e tem que aceitá[...] (Benedita).
[...] eu passei 3 luto de morte da família né! Mas faze o que? Tem que conformá com o que Deus faz. Tudo que Deus faz é bom![...] (Divina).

[...] porque a vida e a morte ta na mão de Deus né, a gente tem o dia de vir no mundo e o de saí também, tudo é permissão de Deus [...] (Eva).

Percebemos nos relatos que a fé e as crenças religiosas permitem às viúvas compreender a morte do esposo como um "chamado" de Deus. O caráter universal deste "chamado divino" correlaciona-se a universalidade da morte, pois, todos um dia vão morrer. Isso dá ao enlutado uma explicação para perda e facilita a sua aceitação por considerar a morte como parte da obra divina. A fé em Deus torna possível a superação da crise desencadeada pela falta de explicação da perda ${ }^{(14)}$.

[...] acredito que ele tá em bom lugar, porque ele era muito bom né [...] então eu espero que ele ta bem né [...] (Benedita).

A fala acima ilustra a afirmativa de que um grande número de religiões judaico-cristãs encara a percepção de futuro como a expectativa de uma conquista para a qual estamos avançando. A perspectiva de imortalidade para elas é a de uma perspectiva futura que dinamiza o presente e atua sobre ele, uma vez que a qualidade de vida depois da morte vai depender das ações realizadas no aqui e agora. Portanto, a perspectiva do futuro está vinculada a ação no presente e a futuridade é percebida como uma conquista para a qual se está avançando, a qual vai depender das ações no presente.

Falar sobre a morte no ambiente cristão está imbuído de imagens e conceitos vinculados à esperança. No mundo protestante, a morte está relacionada com salvação e encontro com o divino. A fé das pessoas expressa um arcabouço teológico de experiência pessoal e familiar ${ }^{(14)}$.

Ao analisarmos a fala de Divina, percebemos sua racionalização sobre a vida após a morte baseada nos conceitos aprendidos na religião evangélica:

[...] depois da morte vem a salvação. Que a gente morre, mas num é no mesmo dia que a gente é salvo, no final né, no julgamento, no julgamento. Aí que a gente vai sabê né [...] (Divina). 
Observamos nesse caso que a religião fornece subsídios conceituais que fomentam a crença na vida após a morte, sendo que estes conceitos, invariavelmente, geram diferentes visões e significados sobre a morte e o luto. É importante salientar que, apesar de todas as religiões apresentarem alguma visão sobre a vida após a morte do corpo, divergências dogmáticas são comuns. Isto reitera a necessidade de se conhecer o sistema religioso da pessoa enlutada, a fim de compreender quais elementos religiosos determinam o significado do luto.

Outro ponto importante dentro desta categoria diz respeito ao luto em casos de doenças graves e incapacitantes. Nestes casos, é comum o processo de luto ocorrer com a pessoa ainda viva, onde a ideia de perda já é elaborada, em ambos os lados constituindo o que se denomina luto antecipatório. Muitas vezes, este processo pode gerar sentimentos ambivalentes naquele que cuida, surgindo o desejo de que o cônjuge morra para aliviar o sofrimento de ambos, despertando a culpa por tais sentimentos ${ }^{(4)}$.

A fé possibilita ao indivíduo pedir a morte do ente querido para aliviar o sofrimento. Ao atribuir a Deus a "decisão" pela morte do cônjuge parte da culpa é aliviada, pois a decisão final de acabar com o sofrimento através da morte não lhe cabe mais:

[...] ele ia sofrer muito, e a gente também né. Ai, entreguei na mão de Deus, falei: meu Jesus faz o que é melhor pra ele né! E Deus feiz! [...] (Benedita).

\section{A Igreja e os rituais religiosos como suporte no processo de luto}

O papel da religião é em parte o de socializar e dirigir os ritos de morte como forma de lidar com o terror. As crenças e rituais que oferecem uma explicação para a morte e apoio social para expressão do pesar deveriam reduzir a confusão e possuir valor psicológico para expressar a dor. Entretanto, a cultura ocidental tende a minimizar e desqualificar os rituais de luto, importantes para a construção de um significado para a perda que auxilie o enfrentamento do luto(4). Durante toda a história humana e em todas as culturas, os rituais de luto facilitaram não apenas a integração da morte, mas também as transformações dos sobreviventes. Nos tempos atuais, passou-se a esconder a morte, tornando o processo de adaptação ainda mais difícil(14).

No discurso de Amélia, não só a realização dos rituais permitiu a construção de um significado positivo para o momento da morte, mas também, as crenças e o simbolismo em que estão mergulhados esses ritos foram verbalizados como importantes:

[...] dae o padre veio aqui, da igreja São Francisco, veio aqui rezou por ele, passou aquela unção, o óleo né! Passou na testa dele, peito, rezou por ele ali, mas foi uma beleza o que ele fez! [...] ajudou que morreu que nem passarinho, $e$ que fizeram lá na capela no cemitério [...] (Amélia).

Um ritual, em um sentido amplo, é uma ação expressiva de anseios comuns, ligados a valores comuns e realizado coletivamente. Assim, um ritual racional (diferente do ritual irracional de característica obsessivocompulsiva) tem por função exprimir anseios que são reconhecidos como valiosos pelo indivíduo. Ainda, outro aspecto deve ser considerado, o aspecto semântico. As religiões, tanto em seus ensinamentos quanto em seus rituais, usa uma linguagem simbólica. Essa essência simbólica é a expressão sensorial de experiências íntimas, de pensamentos e de sentimentos ${ }^{(18)}$.

O suporte social, da comunidade, familiar, religioso e profissional recebido após a morte de uma pessoa querida é fator extremamente relevante para o enfrentamento do luto ${ }^{(19)}$. Estudos têm mostrado efeitos positivos do suporte social religioso no bem-estar psicológico de enlutados ${ }^{(9)}$.

Os religiosos são uma fonte tradicional de apoio e a pessoa religiosa geralmente encontra uma boa fonte de suporte espiritual e social(20). As viúvas entrevistadas mencionaram o suporte social religioso, configurado pelos "irmãos da igreja", como essencial para boa adaptação ao luto do esposo:

[...] isso [frequentar a igreja] é muito melhor pra gente [..]. (Amélia).

[...] a minha igreja, as minhas irmãs da igreja vem faze visita, telefona, pergunta: como é que cê ta? [...] então a minha igreja deu bastante suporte..." (Dulce).

[...] a irmandade da igreja também tem me dado muita força, muita visita [...] por mim eu nem pousava aqui, ia pra 
casa das amigas, das irmãs né, e eu graças a Deus to tendo muita força [...] (Eva).

A igreja, neste contexto, não se refere apenas ao edifício onde se celebram os ritos religiosos. Trata-se da comunidade ou do conjunto de fiéis que professam a mesma fé(13). Portanto, não trazemos o termo igreja como uma instituição dom dogmas, ritos e hierarquias definidos, mas sim como um grupo de indivíduos na sociedade que se inter-relacionam mediados pela mesma crença.

Fica evidente nos relatos anteriores que o apoio prestado pela "irmandade" foi importante na vivência do luto. Este resultado corrobora com outro estudo ${ }^{(14)}$ onde a presença cuidadora também está focada na comunidade religiosa, que expressa solidariedade no momento da perda.

Ainda, percebemos nos relatos que a religiosidade extrínseca (cultos, grupos de oração) configura-se em um importante espaço de convívio e interação social:

[...] a gente faz um encontro de vivência que se ajunta na minha casa, se ajunta na casa do outro vizinho, a gente já reza, já pede pra pessoa também, é tudo assim unido [...] (Cecilia).

Componentes de religiosidade extrínseca como participação em cultos e o atendimento dado por religiosos não apresentam os mesmos efeitos benéficos que os componentes mais espirituais ${ }^{(9)}$. Entretanto, em nosso estudo observamos que os componentes extrínsecos de religiosidade se mostraram importantes por proporcionar às viúvas espaços de socialização e de expressão de sentimentos, essenciais para a elaboração do luto.

\section{CONSIDERAÇÕES FINAIS}

Tendo como base os achados descritos acima, podemos inferir que a crença em Deus mostrou-se como um forte elemento construtor de significado orientado

\section{REFERÊNCIAS}

1. Brito F. Transição demográfica e desigualdades sociais no Brasil. Rev bras estud popul. 2008;25(1):5-26.

2. Motta CCR, Hansel CG, Silva J. Perfil de internações de pessoas idosas em um hospital público. Rev. Eletr. Enf. [Internet]. 2010 [cited 2012 sep 30];12(3):471-7. Available from:

http://dx.doi.org/10.5216/ree.v12i3.6865. para a restauração do luto. A religião forneceu às viúvas uma "explicação" para a morte do marido. Tanto as crenças na vida após a morte quanto o significado da morte como um "chamado divino", permitiu às enlutadas aceitar a perda de maneira satisfatória.

A Igreja, entendida como a comunidade de fiéis que compartilham a mesma fé, proporcionou às viúvas espaço de socialização e de expressão de sentimentos, servindo como apoio essencial na elaboração do luto. A fé em Deus foi utilizada como estratégia de enfrentamento da ansiedade gerada pela saudade e busca da figura perdida. Tanto elementos de religiosidade intrínseca quanto extrínseca, foram verbalizados como protetoras da depressão e de sentimentos de tristeza ligados à solidão.

A ciência, em sua história, atribuiu um caráter negativo à religião, na maioria das vezes psicopatológico, criando uma lacuna entre a religiosidade/espiritualidade e seu verdadeiro papel na saúde mental das pessoas. A síntese acima evidencia que a espiritualidade, expressa como a fé e a crença em Deus, e a religião, possuem um papel mais positivo na elaboração do luto do que se atribui comumente na literatura.

Portanto, novas pesquisas devem buscar compreensão mais aprofundada do papel positivo da religiosidade/espiritualidade na vida das pessoas, devolvendo à religião aquilo que the foi segregado no processo de secularização. Ressaltamos que essa busca deve ser desenvolvida por olhos distraídos dos dogmas religiosos existentes, evitando a defensoria desta ou daquela religião específica.

Ainda como recomendação, sugerimos que novas pesquisas a respeito da construção de significado da morte e do luto contemplem indivíduos de características e crenças mais diversificadas quanto possível. Do ponto de vista prático, estes resultados devem chamar a atenção para que os profissionais que lidam com situações de luto e morte busquem integrar as crenças religiosas dos indivíduos sob seus cuidados na elaboração satisfatória do luto.

3. Carvalho JAM, Rodríguez-Wong LL. A transição da estrutura etária da população brasileira na primeira metade do século XXI. Cad. Saúde Pública 2008; 24(3): 597-605.

4. Parkes CM, Prigerson HG: Bereavement: studies of grief in adult life. 4th ed. New York: Routledge; 2009. 
5. Hansson RO, Stroebe MS. Bereavement in late life: coping, adaptation, and developmental influences.1st ed. Washington: American Psychological Association; 2007.

6. Oliveira JBA, Lopes RC. O processo de luto no idoso pela morte de cônjuge e filho. Psicologia em Estudo. 2008;13(2):217-21.

7. Kovács MJ. Desenvolvimento da tanatologia: estudos sobre a morte e o morrer. Paidéia (Ribeirão Preto). 2008;18(41):457-68. 8. Laranjeira CASJ. Do vulnerável ser ao resiliente envelhecer: revisão de literatura. Psic Teor e Pesq. 2007;23(3):327-32.

9. Hays JC, Hendrix CC. The role of religion in bereavement. In: Stroebe MS, Hansson RO, Schut H, Stroebe W, editors. Handbook of bereavement research and practice: advances in theory and intervention. Washington: American Psychological Association; 2008. p. 327-348.

10. Silva Al, Alves VP. Envelhecimento: resiliência e espiritualidade: história de vida de idosos: superar a adversidades sem perder o senso de integridade. Diálogos possíveis. 2007;6(1):189-209.

11. Turato ER. Tratado da metodologia da pesquisa clínicoqualitativa. 4th ed. Petrópolis: Vozes; 2010.

12. Fontanella BJB, Ricas J, Turato, ER. Amostragem por saturação em pesquisas qualitativas em saúde: contribuições teóricas. Cad. Saúde Pública 2008;24(1):17-27.

13. Ferreira, $A B H$. Mini Aurelio: dicionário da língua portuguesa. 8th ed. Curitiba: Editora Positivo; 2010.

14. Paula B. Corpos enlutados: por um cuidado espiritual terapêutico em situações de luto [thesis]. São Paulo: Faculdade de Humanidades e Direito/UMESP; 2009. 370 p.

15. Bjarnason D. Concept analysis of religiosity. Home Health Care Manag Pract. 2007. 19(5):350-5.

16. Weiss RS. The nature and causes of grief. In: Stroebe MS, Hansson RO, Schut $H$, Stroebe W, editors. Handbook of bereavement research and practice: advances in theory and intervention. Washington: American Psychological Association; 2008. p. 29-44.

17. Muckulincer $M$, Shaver PR. An attachment perspective on bereavement. In: Stroebe MS, Hansson RO, Schut H, Stroebe W, editors. Handbook of bereavement research and practice: advances in theory and intervention. Washington: American Psychological Association; 2008. p. 87-112.

18. Fromm E. Psicanálise e religião. Rio de Janeiro: Livro íberoamericano; 1966.

19. Mazorra L. A construção de significados atribuídos à morte de um ente querido e o processo de luto [thesis]. São Paulo: Departamento de Psicologia Clínica/PUC; 2009. 253 p.

20. Bousso RS, Poles K, Serafim TS, Miranda MG. Crenças religiosas, doença e morte: perspectiva da família na experiência de doença. Rev. esc. enferm. 2011;45(2):397-403.

Artigo recebido em 23/05/2011.

Aprovado para publicação em 10/05/2012.

Artigo publicado em 30/09/2012. 